\title{
Evaluation of latent heat storage in mortars containing microencapsulated paraffin waxes - a selection of optimal composition and binders
}

\author{
S. S. Lucas ${ }^{1,2}$ (D) J. L. Barroso de Aguiar ${ }^{3}$
}

Received: 2 August 2018 / Accepted: 8 February 2019 /Published online: 20 February 2019

(C) The Author(s) 2019

\begin{abstract}
The application of phase change materials (PCMs) in mortars have been extensively researched, however, most studies are focused in one single binder. Conducting comparative assessments using different binders can facilitate the development of compositions with adequate heat storage and suitable mechanical properties. In this work, several PCM-mortars using cement, lime and gypsum as binders, have been studied using a laboratory simulation that mimicked the day/night temperature changes that the material will be subject during service applications. It has been demonstrated that the addition of PCMs in mortars allows the material to retain heat, indicating that these mortars can have a positive impact on the overall energy demand of buildings. There is a combined effect of delay and lowering of temperature peaks, triggered by the heat released from the capsules. The cells with PCMs showed not only a smaller temperature gradient between night and day, but it also exhibited lower peaks. The tests conducted with this laboratory setup prove that PCMs can be successfully mixed into mortars without compromising its durability, hence their applicability as wall renderings.
\end{abstract}

\section{Introduction}

Increasing the cost of energy and raising concerns with the environmental impact of construction has put pressure on industry to seek solutions that can reduce the life cycle impact of buildings. The application of phase change materials (PCMs) in building's structures and products had been subject to extensive research, due to its potential for reducing heating and cooling needs within buildings [1-3].

PCMs can store a high amount of energy per mass of material and latent heat storage occurs at an almost constant temperature. They suffer low volume changes, thus making it a

\section{S. S. Lucas}

s.s.d.o.lucas@tue.nl

1 Department of the Built Environment, Unit of Structural Design, Eindhoven University of Technology, PO Box 513, 5600 MB Eindhoven, The Netherlands

2 University of Aveiro, CICECO, Campus Santiago, 3810 Aveiro, Portugal

3 Department of Civil Engineering, University of Minho, Campus de Azurém, 4800-058 Guimarães, Portugal very interesting material for incorporation into mortar composites. Latent heat transfer that occurs at the phase change temperature is a direct result of the PCM's melting/solidifying process [4].

Latent heat storage is then dependent on the enthalpy change and can be determined using Eq. 1, where $\Delta H$ is the enthalpy variation and $\mathrm{m}$ is the material mass.

$\Delta \mathrm{Q}=\mathrm{m} \times \Delta \mathrm{H}$

The main advantage of using PCMs in buildings is the possibility of using its high amount of latent heat, stored or released during the phase transition. Latent heat storage can be evaluated by the heat release or absorption occurring when the state changes from liquid to solid or vice-versa.

An ideal PCM can be characterised by its specific heat $\mathrm{c}_{\mathrm{p}}$, the phase-change enthalpy $\Delta \mathrm{h}$ and its melting temperature $\mathrm{T}_{\mathrm{m}}$. a real PCM, however, needs to be described by a function $\mathrm{h}(\mathrm{T})$. For materials containing PCMs, the storage capacity is then determined by

$\mathrm{Q}=\int_{\mathrm{T}_{1}}^{\mathrm{T}_{2}} \mathrm{mc}_{\mathrm{p}} \mathrm{dT}+\mathrm{mf}_{\mathrm{m}} \Delta \mathrm{h}$

So storage capacity between temperatures $T_{1}$ and $T_{2}$ is given by the stored heat $\mathrm{Q}$ and depends on mass (m), specific 
heat, the fraction of material undergoing phase change $f_{m}$ and the change in enthalpy. When the PCM is at the heating stage at constant pressure, without a phase transition, the enthalpy change for a mass $\mathrm{m}$ and heat capacity $\mathrm{C}$, will be given by

$\Delta H=\int_{T_{1}}^{T_{2}} C d T$

As the heating progresses, the PCM reaches its phase transition point at temperature $T_{m}$ and then enthalpy changes. The enthalpy change for the melting process can be determined using Eq. 4. During the cooling stage, the same amount of heat will be released into the system.

$\Delta \mathrm{H}=\int_{\mathrm{T}_{1}}^{\mathrm{T}_{\mathrm{M}}} \mathrm{CdT}+\Delta \mathrm{H}_{M}+\int_{\mathrm{T}_{\mathrm{M}}}^{\mathrm{T}_{2}} \mathrm{CdT}$

Phase change materials undergoing solid-liquid transformations - the ones used in building applications - can be divided into two main types, organic and inorganic. They can also be eutectic compositions - with a single temperature point for changing phase, or mixtures - where the temperature occurs at a very narrow interval [3]. For construction applications, both types including eutectic and mixtures have been studied. Eutectic compositions, using fatty acids still show limited success, increased costs, processing difficulties and safety issues. The loss in mechanical strength and the leakage risk are not adequately compensated by a substantial increase in performance [5], what makes them less interesting for an industry where materials have to meet tight regulations and still have low cost. Paraffin waxes proved to be more costeffective, they are commercially available at a relatively low cost and are less detrimental for hardened state properties, allowing higher percentages of PCMs to be added [6].

One of the important aspect to address when considering the incorporation of PCM in mortars is leakage, often associated with safety concerns and loss of performance [7]. The problem has been overcome by encapsulation methods that keep the PCM contained in polymer capsules. The capsules' size is small enough to be accommodated by the mortar's internal porosity [8], the shell is also capable of resisting the mixing and application processes without breaking. The use of polymethyl methacrylate (PMMA) capsules has been proven quite successful with cement, lime and gypsum matrices [9].

This combination of microencapsulated PCM with mortars does not come without challenges, though. The introduction of these capsules into a cement matrix increases its internal porosity, having a negative impact on the final mechanical strength [10]. The phenomenon is not exclusive of cement, it is also seen with other hydraulic binders [11]. Some authors concluded that the presence of the paraffin waxes reduces the heat of hydration, aggravated when the capsules break during mortars' processing. Adding silica fume or fly ash - to improve the hydration process at an early stage or long-term - can help to overcome this problem [12]. It is also important to note that, despite sometimes a significant reduction in mechanical strength, the overall numbers are high enough to allow its use in many structural and non-structural applications [13].

Although research with cement and concrete is the one that has produced more outputs so far, there is also a growing interest in exploring the mixing of PCMs with alternative binders. What is remarkable here is that, for example, hydrated lime mortars - when mixed with PCM capsules - can retrieve very different results, compared with cement [11]. This is clearly connected with the internal porosity of the lime mortars, how the capsules of PCM can fill and fit into the microstructure. It seems that PCMs can partially fill the pores of lime mortars much better than in cement compositions, mitigating the loss of mechanical strength, in some cases even improving it. The effect extends even to lime mortars that combine PCMs and other additives. This is the case with a recent work where paraffin microcapsules and titanium dioxide nanoparticles have been added to a lime mortar. The presence of the PCM improved the mechanical strength of the mortars containing nanoparticles [14].

Unquestionably, lime mortars have lower mechanical strengths relative to cement, yet, for application in buildings' renovation, the possibility of adding heat storage can be important for reducing the overall energy demand. If it is possible to do it while having an improvement on mortar's durability, then PCM-lime composites are, no doubt, very attractive for applications in cultural heritage preservation.

\section{Materials}

The compositions were prepared using three commercial binders: hydrated lime, Portland cement CEM II $32.5 \mathrm{~N}$ and gypsum. A siliceous sand, with an average particle size of $0.4 \mathrm{~mm}$, was used as fine aggregate. To reduce the water intake while maintaining workability, $1 \mathrm{wt} . \%$ of superplasticizer was added to all mixes.

The phase change material is a mixture of paraffin waxes encapsulated in a polymethylmethacrylate (PMMA) shell, with an average (agglomerated) particle size of $6 \mu \mathrm{m}$, a transition temperature of $23{ }^{\circ} \mathrm{C}$ and enthalpy of $135 \mathrm{~kJ} / \mathrm{kg}$. The PCM content ranges from 0 to $30 \%$ in weight of total solids. In this work, the PCM was always added as an additive and not as a replacement for binder or aggregates. This decision was made based on evidence that the PCM cannot be considered either a binder or an aggregate. Other studies have been conducted using one of these strategies, however since is a material that provides a new functionality, the authors decided to include the PCM as an additive, not a replacement.

Adding more than $30 \mathrm{wt} . \%$ proved to be challenging though, causing a considerable reduction in workability due to the high surface area, therefore, for the purpose of this work, a maximum limit of $30 \%$ in weight was established. 


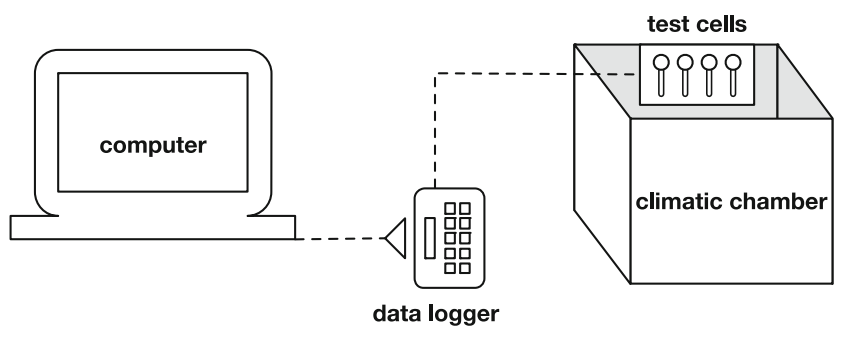

Fig. 1 Schematic drawing for the laboratory set-up

This is in line with other researchers work where additions of 40 and $60 \mathrm{wt} . \%$ proved to cause a decrease in strength and no substantial improvement in latent heat storage to justify the added cost [3].

\section{Experimental}

\subsection{Hardened state properties}

For the compression and flexural strength tests, the samples were prepared and tested according to the European Standard

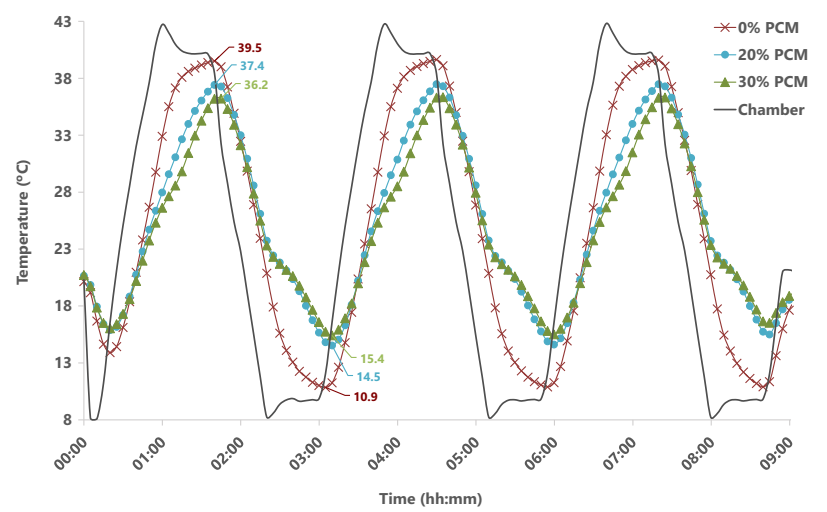

a

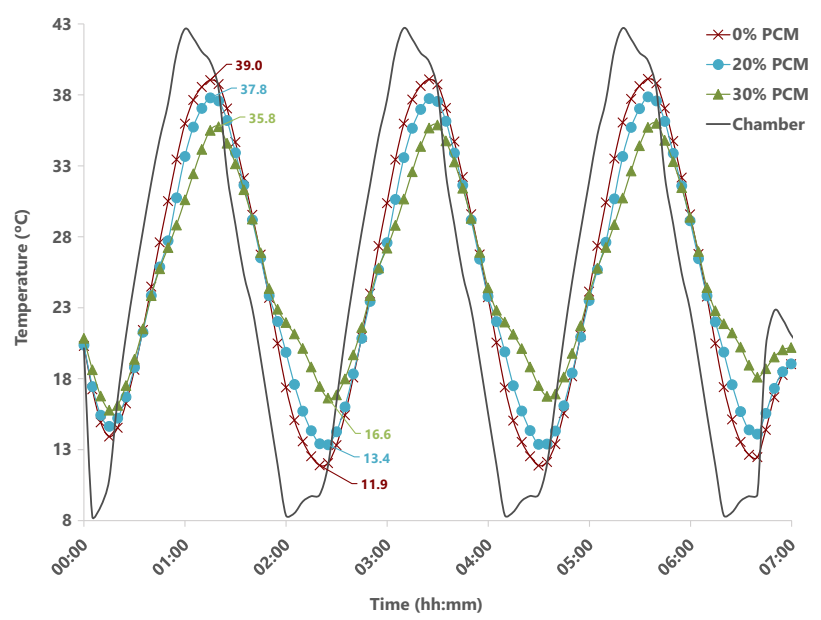

C
EN 1015-11:1999 [15]. The open porosity and water absorption were done following the European Standard EN 101510:1999 [16].

\subsection{Laboratory tests - heat storage}

While conceiving the laboratory tests for assessing the heat storage performance, the authors' main objective was to mimic as reliably as possible the temperature fluctuations in real outdoor conditions. The tests cells, with a size of $200 \times 200 \times$ $200 \mathrm{~mm}$, were coated in 4 inner faces with a mortar layer with $3 \mathrm{~mm}$ thickness, spread through a layer of $100 \times 100 \mathrm{~mm}$. Each box was equipped with a thermocouple placed at the centre of the cell, to measure the environmental temperature - thermocouples were also placed at the mortar's surface to determine if there were differences relative to the environmental measurement.

The schematic experimental setup can be seen in Fig. 1. The cells were placed inside a climatic chamber under controlled humidity levels. It was established a cycle with a minimum temperature of $10^{\circ} \mathrm{C}$ and a maximum of $40^{\circ} \mathrm{C}$, with a

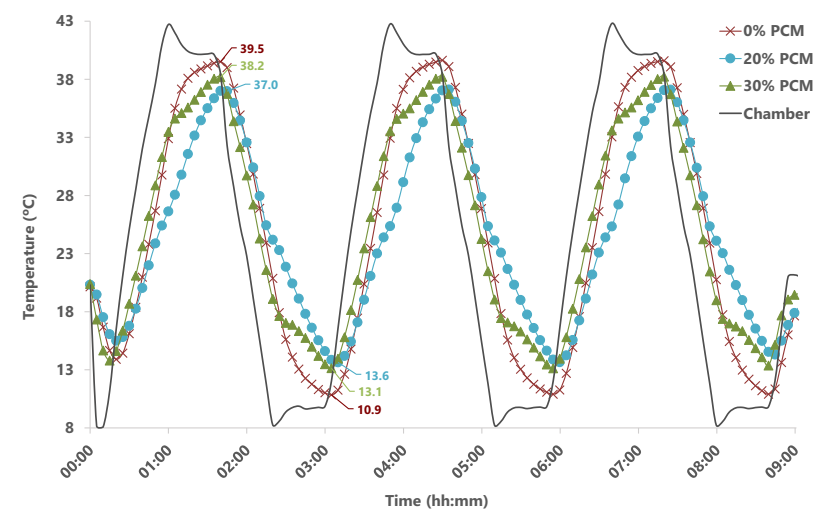

b

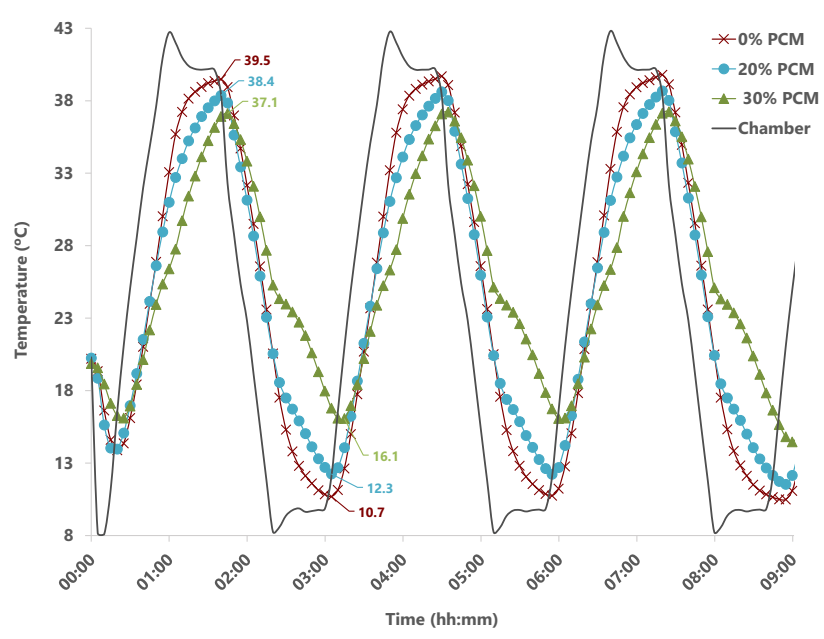

d

Fig. 2 Temperature cycles for a cement, $\mathbf{b}$ cement-lime, $\mathbf{c}$ lime and $\mathbf{d}$ lime-gypsum 


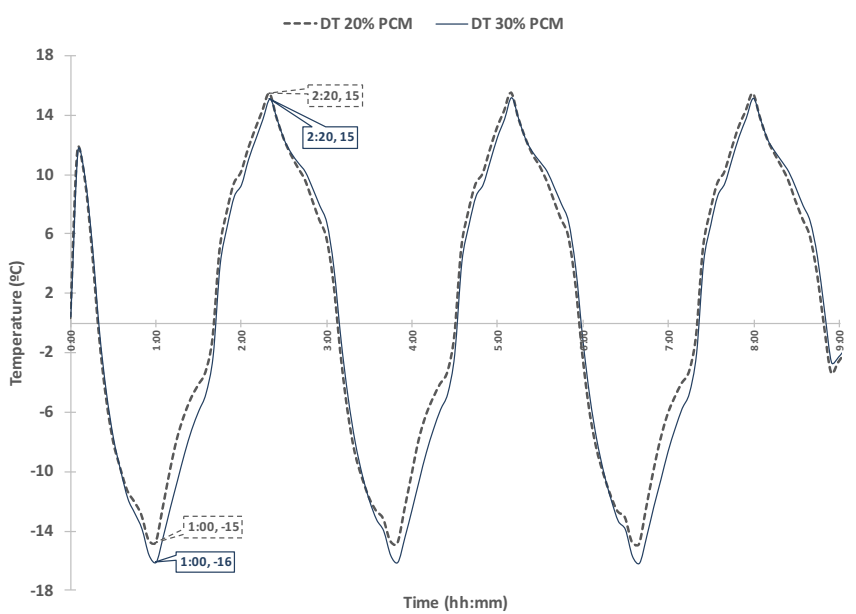

a

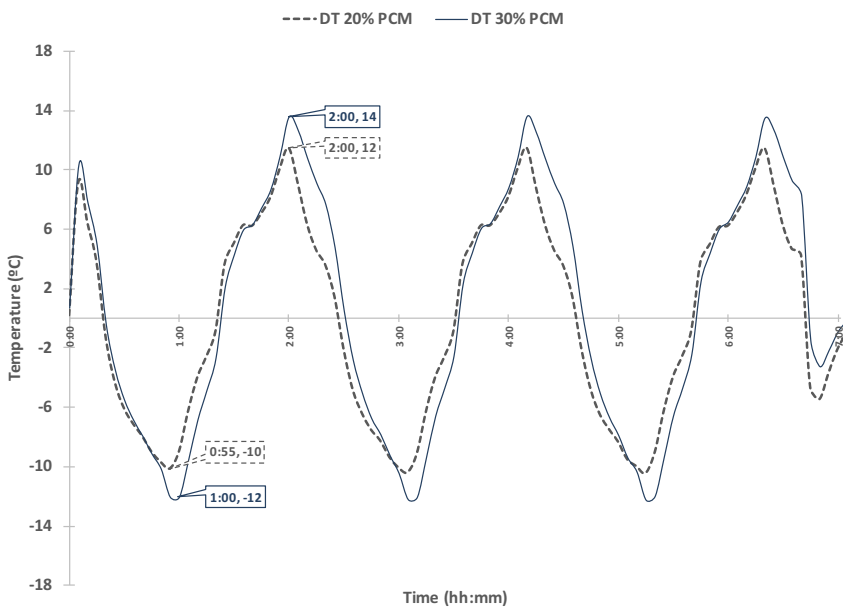

C

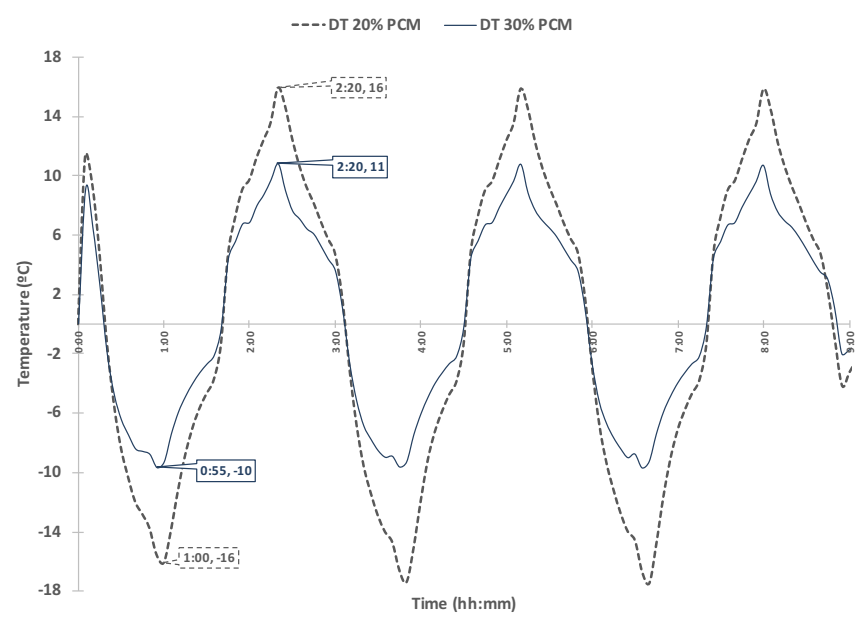

b

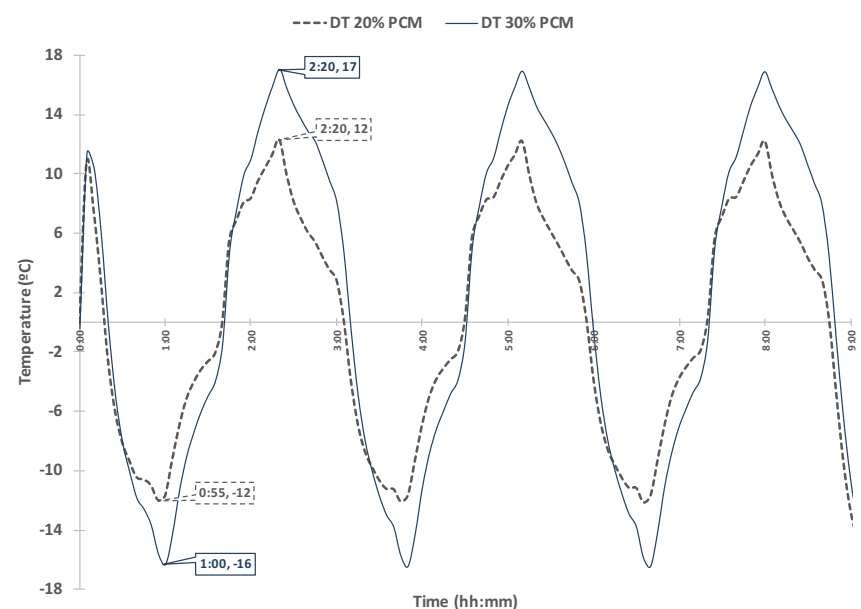

d

Fig. 3 Temperature gradient for a cement, $\mathbf{b}$ cement-lime, $\mathbf{c}$ lime and $\mathbf{d}$ lime-gypsum

steady-state period of $10 \mathrm{~min}$ at the maximum and minimum values. With this cycle, the PCM - having a phase transition around 23 to $25{ }^{\circ} \mathrm{C}$ - is always subject to a phase change during heating and cooling.

\section{Discussion}

\subsection{Climatic chamber tests}

Figure 2 presents the results of the tests performed using the climatic chamber. However, efficacy differs for different binders, it is clear that all mortars with PCMs are able to delay and reduce temperature peaks. PCM-mortars appear though to be more effective during cooling cycles, where not only the peak temperature shows a higher difference to the reference cell, but also the delay is more notable. The cells are still useful for heating periods, even if the benefit is less significant, it will still be enough to reduce the energy demand for cooling.

This observation, that microencapsulated PCMs are more adequate for cold climates while applications for cooling appear to be less interesting, is in line with other authors' findings.

It is worth noticing that lime-based mortars are amongst the most efficient, showing lower peaks - especially during cooling. The lime-cement mortar is the only composition where the 20 wt.\% PCM shows higher efficiency than the $30 \mathrm{wt} . \%$. The explanation for both phenomena is detailed in a previous publication [17]. It has been proven that internal microstructure plays an important role in PCM-mortars performance, not only influences the mechanical strength but also affects the heat storage efficiency.

It is indisputable that cement-PCM composites have been, by far, the most studied with the application of PCMs targeting mainly new buildings. The results obtained in this study with hydrated lime prove, however, that PCM-mortars can also be 

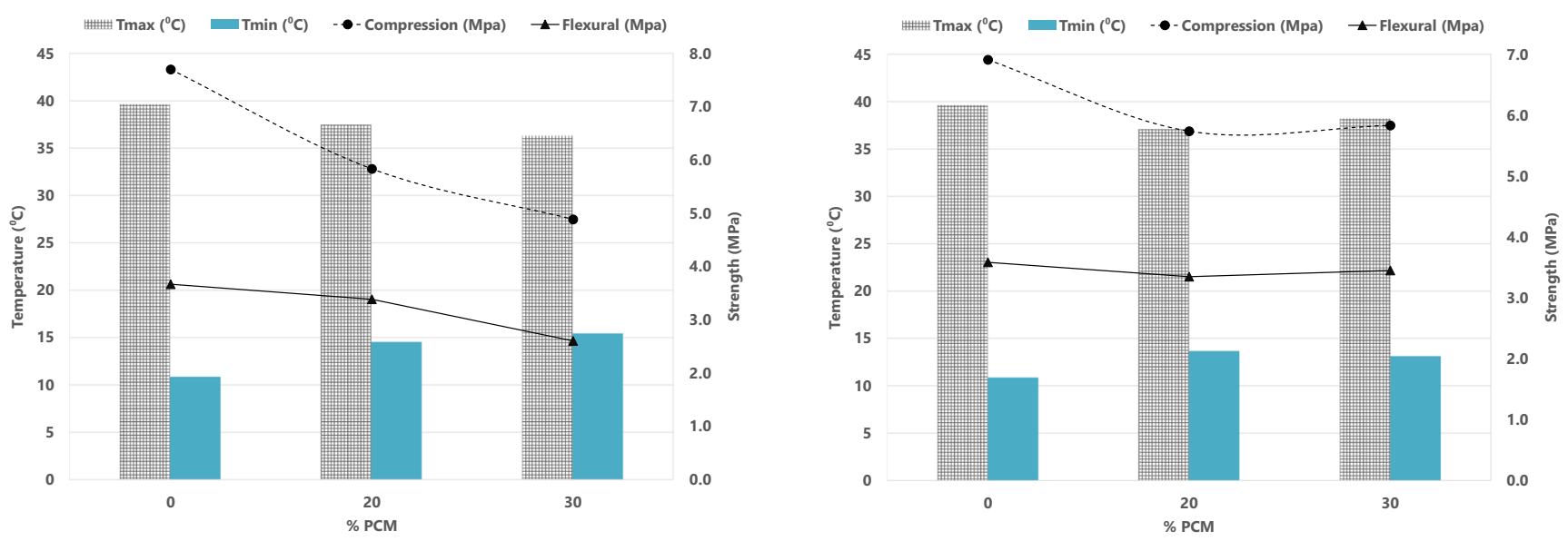

a

b
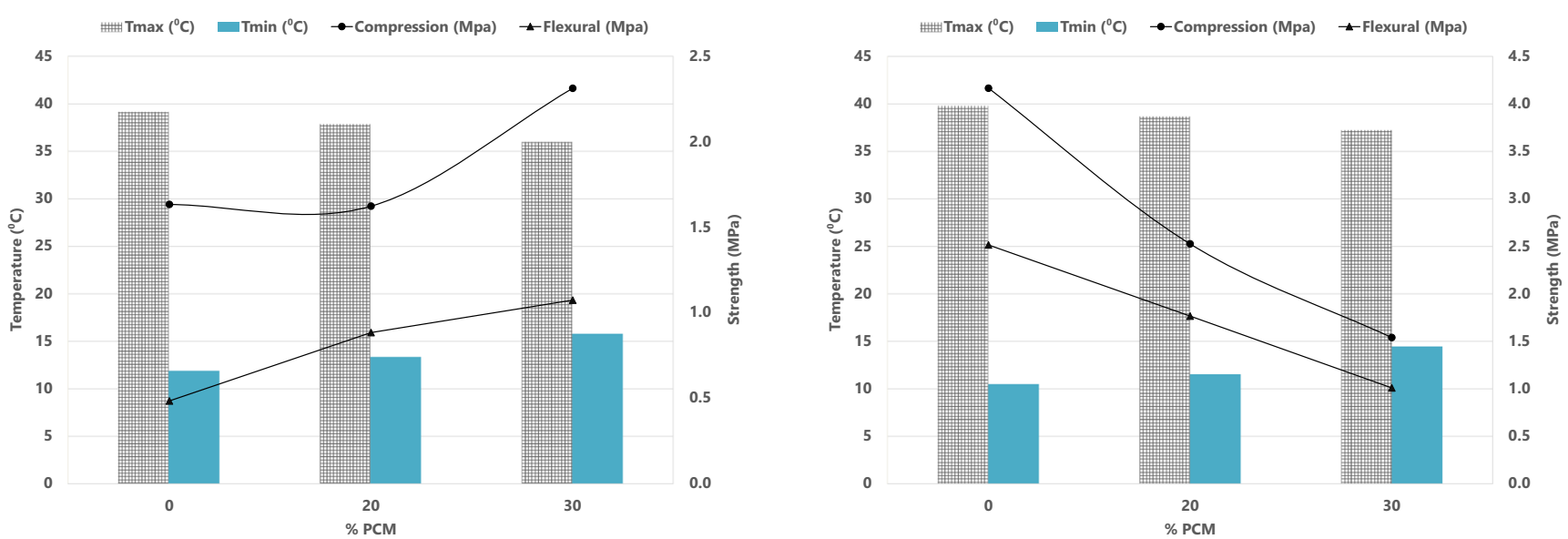

C

d

Fig. 4 Comparison between mechanical strength and the maximum and minimum temperature achieved per each composition, a cement, $\mathbf{b}$ cement-lime, c lime and d lime-gypsum

integrated into buildings' retrofit. Because they can be prepared the same way as a traditional lime mortar, its use can

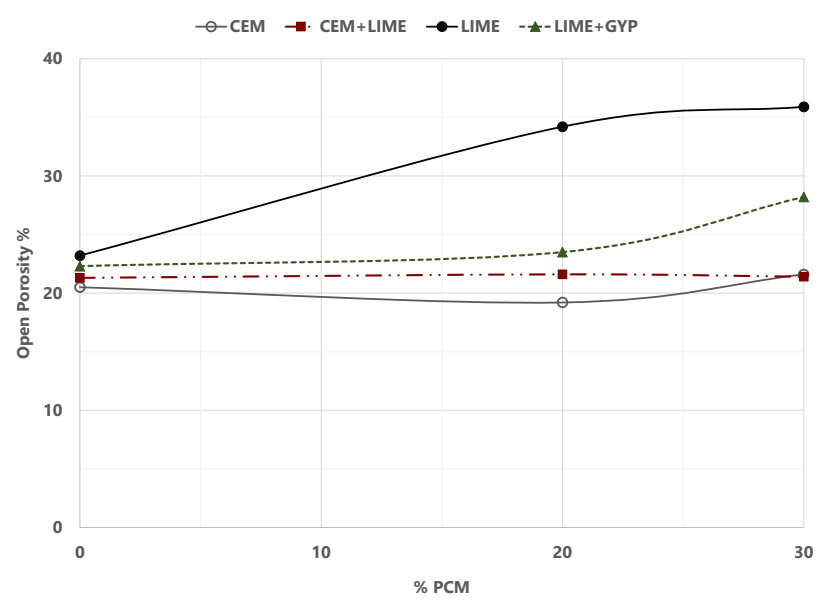

a contribute to higher energy efficiency in old buildings, without the need for extensive or complex interventions.

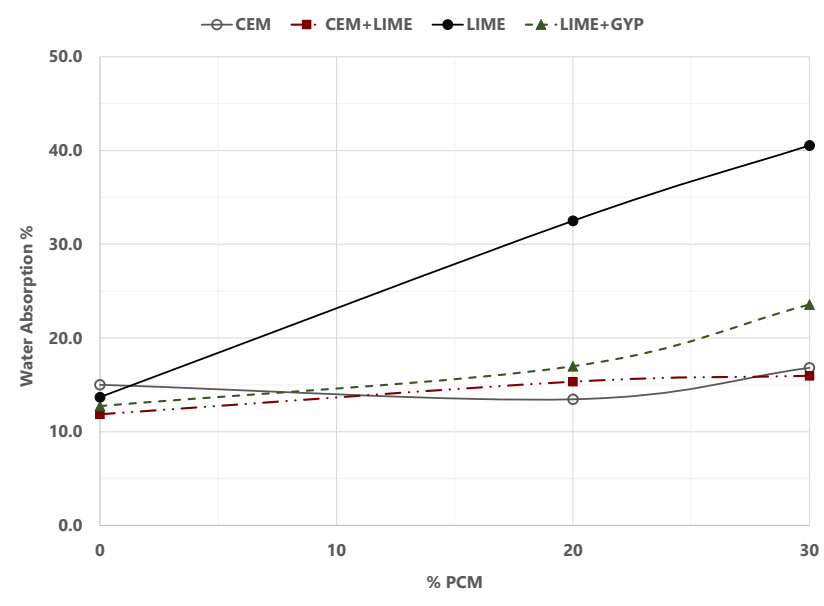

b

Fig. 5 Open porosity (a) and water absorption (b) 
When assessing the performance of PCM-mortars one needs to have a look at the not only the temperature peaks but also the attenuation factor, as shown in Fig. 3. While it is clear that, the highest value during heating is only slightly below the maximum achieved for the reference cell, the time taken to reach that peak is clearly slower with the PCM-mortars.

In Fig. 3, the values show the difference between the temperatures inside the PCM cell relative to the temperatures measured in the chamber. Heating stages correspond to the negative values and cooling stages are the positive side of the charts. The highest gradients during heating are found with the PCM-cement, exhibiting up to minus $16{ }^{\circ} \mathrm{C}$ after $1 \mathrm{~h}$. Interesting to point out that for the limecement composition a higher content of PCMs is, in fact, detrimental, with the temperature gradient going from $16{ }^{\circ} \mathrm{C}$ with $20 \%$ to only $10{ }^{\circ} \mathrm{C}$ for $30 \%$. This has been discussed before by Lucas et al., showing how complex the addition of micro-sized additives to porous materials can be. The microstructure, the pore size and its distribution seem to be more relevant to the overall performance than the amount of PCMs in itself.

It is not possible to determine which compositions show better potential for application without discussing the mortars' durability.

Durability is highly dependent on mechanical strength and in Fig. 4 a correlation between mechanical strength and thermal performance can be found. Cement mortars even though exhibiting a loss of mechanical strength are still in a high range and it can be concluded that adding PCM microcapsules does not compromise use. Adding lime to cement helped reduce the loss in compression strength and kept the flexural strength almost constant. Considering that this is the only composition with a higher efficiency for $20 \%$ of PCM, it makes this mix interesting for real service applications - fewer PCM added means a lower final cost. The lime mortar is the only composition showing a remarkable increase in strength with the incorporation of PCMs, adding this to the energy savings that can be achieved, makes the limePCM-mortar especially interesting for retrofitting. The lime-gypsum composition has the highest loss of strength, to a level that can impair its application. This though can be prevented by adding fibres to the mix.

It is somehow surprising that substantial increase in open porosity and water absorption for the lime composition does not have an impact in the mechanical strength (Fig. 5). Notably, the strength increases, which is indeed contrary to what would be expected from these results. This shows that the paraffin microcapsules, despite not being able to close the open pores are capable of reducing the internal porosity so much that mechanical properties can be improved.

Nonetheless, this is an important factor to consider when assessing durability since open pores can contribute to an increased degradation of lime mortars. Yet, it is important to note that open porosity within the range of $30-35 \%$ is not unusual for lime renders and mortars with $30 \%$ of PCMs are still eligible for application in old buildings for rehabilitation and conservation purposes - according to the European Standard EN 998$1: 2010$ [18, 19].

For the cement compositions, there are no significant changes in open porosity and water absorption but the loss of mechanical strength for the cement mix is an indication that internal pores have increased. The same effect can be seen for the lime and gypsum mixture, where the loss of strength is even more pronounced.

By looking at the results, it is fair to state that the limecement composition is by far the most promising, achieving a very good performance for heat storage while maintaining a high level of mechanical strength, with stable open porosity and water absorption.

\section{Conclusion}

It has been demonstrated that mortars containing PCMs can effectively store heat and release it at a later stage, providing a suitable complement to thermal insulation that can contribute to reducing the cost of energy in buildings. The fact that different binders have been tested provides a good insight into the viability of PCM-mortars for use not only in new structures but also in old buildings rehabilitation.

During these tests, a thin layer of approximately $3 \mathrm{~mm}$ was used, showing that the solution can be applied in the same way as the final standard finishing layer that is currently used in buildings. According to the standard EN 998-1:2010 all compositions show adequate strengths for application as rendering mortars, with cement mortars falling into category CS III and lime and lime-gypsum compositions in category CS II [19]. Lime containing mortars exhibited no loss of strength even when up to $30 \%$ of PCM was added, what has also been confirmed by other studies where similar percentages have been tested.

It is though important to bear in mind that an increase in PCM also has an impact on the mortars' final cost so, it is the authors' understanding that $20 \mathrm{wt} . \%$ will be the best compromise between mechanical strength, thermal performance and potential for energy saving for these coatings.

Acknowledgements Part of this work has been supported by the grant PTDC/ECM/72104/2006 awarded by the Foundation for Science and Technology (FCT).

Open Access This article is distributed under the terms of the Creative Commons Attribution 4.0 International License (http:// 
creativecommons.org/licenses/by/4.0/), which permits unrestricted use, distribution, and reproduction in any medium, provided you give appropriate credit to the original author(s) and the source, provide a link to the Creative Commons license, and indicate if changes were made.

Publisher's note Springer Nature remains neutral with regard to jurisdictional claims in published maps and institutional affiliations.

\section{References}

1. Kheradmand M, Azenha M, de Aguiar JLB, Krakowiak KJ (2014) Thermal behavior of cement based plastering mortar containing hybrid microencapsulated phase change materials. Energy Build 84:526-536. https://doi.org/10.1016/J.ENBUILD.2014.08.010

2. Soares N, Costa JJ, Gaspar AR, Santos P (2013) Review of passive PCM latent heat thermal energy storage systems towards buildings' energy efficiency. Energy Build 59:82-103. https://doi.org/10. 1016/J.ENBUILD.2012.12.042

3. Rao VV, Parameshwaran R, Ram VV (2018) PCM-mortar based construction materials for energy efficient buildings: A review on research trends. Energy Build 158:95-122. https://doi.org/10.1016/ J.ENBUILD.2017.09.098

4. Vicente R, Silva T (2014) Brick masonry walls with PCM macrocapsules: An experimental approach. Appl Therm Eng 67: 24-34. https://doi.org/10.1016/J.APPLTHERMALENG.2014.02. 069

5. He Y, Zhang X, Zhang Y et al (2016) Utilization of lauric acidmyristic acid/expanded graphite phase change materials to improve thermal properties of cement mortar. Energy Build 133:547-558. https://doi.org/10.1016/J.ENBUILD.2016.10.016

6. Wei Z, Falzone G, Wang B et al (2017) The durability of cementitious composites containing microencapsulated phase change materials. Cem Concr Compos 81:66-76. https://doi.org/10.1016/j. cemconcomp.2017.04.010

7. Li X, Sanjayan JG, Wilson JL (2014) Fabrication and stability of form-stable diatomite/paraffin phase change material composites. Energy Build 76:284-294. https://doi.org/10.1016/J.ENBUILD. 2014.02.082

8. Cunha S, Lima M, Aguiar JB (2016) Influence of adding phase change materials on the physical and mechanical properties of cement mortars. Constr Build Mater 127:1-10. https://doi.org/10. 1016/J.CONBUILDMAT.2016.09.119
9. Konuklu Y, Ostry M, Paksoy HO, Charvat P (2015) Review on using microencapsulated phase change materials (PCM) in building applications. Energy Build 106:134-155. https://doi.org/10.1016/J. ENBUILD.2015.07.019

10. Lecompte T, Le Bideau P, Glouannec P et al (2015) Mechanical and thermo-physical behaviour of concretes and mortars containing phase change material. Energy Build 94:52-60. https://doi.org/10. 1016/J.ENBUILD.2015.02.044

11. Theodoridou M, Kyriakou L, Ioannou I (2016) PCM-enhanced Lime Plasters for Vernacular and Contemporary Architecture. Energy Procedia 97:539-545. https://doi.org/10.1016/j.egypro. 2016.10.070

12. Pilehvar S, Cao VD, Szczotok AM et al (2018) Physical and mechanical properties of fly ash and slag geopolymer concrete containing different types of micro-encapsulated phase change materials. Constr Build Mater 173:28-39. https://doi.org/10.1016/J. CONBUILDMAT.2018.04.016

13. Tuncel EY, Pekmezci BY (2018) A sustainable cold bonded lightweight PCM aggregate production: Its effects on concrete properties. Constr Build Mater 181:199-216. https://doi.org/10.1016/J. CONBUILDMAT.2018.05.269

14. Lucas SS, Barroso De Aguiar JL (2018) Multifunctional wall coating combining photocatalysis, self-cleaning and latent heat storage. Mater Res Express 5. https://doi.org/10.1088/2053-1591/aaa82f

15. EN (1999) 1015-11: Methods of test for mortar for masonry-Part 11: Determination of flexural and compressive strength of hardened mortar. European Committee for Standardization, Brussels

16. EN (1999) 1015-10: Methods of test for mortar for masonry-Part 10. Determination of dry bulk density of hardened mortar. European Committee for Standardization, Brussels

17. Lucas SS, Ferreira VM, Barroso de Aguiar JL (2013) Latent heat storage in PCM containing mortars - Study of microstructural modifications. Energy Build 66:724-731. https://doi.org/10.1016/j. enbuild.2013.07.060

18. Veiga R (2017) Air lime mortars: What else do we need to know to apply them in conservation and rehabilitation interventions? A review. Constr Build Mater 157:132-140. https://doi.org/10.1016/J. CONBUILDMAT.2017.09.080

19. EN (2010) 998 Specification for mortar for masonry-Part 1: Rendering and plastering mortar. European Committee for Standardization, Brussels 